\title{
Study on the Dynamics Simulation of Quantity Change in Cultivated Land Resources in Chongqing City
}

\author{
Min Peng ${ }^{1} \&$ Ruiping Ran ${ }^{1}$ \\ ${ }^{1}$ College of Economics and Management, Sichuan Agricultural University, Chengdu, China \\ Correspondence: Min Peng, College of Economics and Management, Sichuan Agricultural University, Chengdu \\ 611130, China. E-mail: susan1392@126.com
}

Received: August 20, 2013

Accepted: August 28, 2013

Online Published: September 7, 2013

doi:10.5430/ijba.v4n5p79

URL: http://dx.doi.org/10.5430/ijba.v4n5p79

\begin{abstract}
This paper uses system dynamics software vensim to simulate the relations between all systems of the quantity of cultivated land resources in Chongqing City. By establishing SD model, it analyzes how the change in the quantity of cultivated land resources influences other systems and how other sub-systems influence the change in the quantity of cultivated land resources. It sets the parameters in the model with the historical data during the years 2002 to 2010 in Chongqing. After a historical examination on them, this paper uses parameter levels in different projects for a simulation influencing analysis. That is, if the cultivated land is used in a large quantity, the reduction speed of the quantity of cultivated land will, instead, be accelerated; and if the per unit yield of grain is increased, the demand on cultivated land will present a linear reduction state.
\end{abstract}

Keywords: cultivated land resources, SD flow chart, system dynamics model

\section{Study Significance and Summary of Study Area}

Cultivated land is the foundation for human survival and social and economic development. The fundamental reality of China is small quantity of per capital cultivated land, bad quality of cultivated land and insufficient reserve cultivated land resources. Ever since the reform and opening up in China, the area of cultivated land has continuously declined, which has brought significant hidden danger to the food security of the country. (Xu Ruixiang, Zhang Yongqin, Ding Jianzhong \& et al., 2002) Chongqing is a municipality in China which has the largest area and is the economic and financial center of the upper reaches of the Yangtze River and also a center of shipping, politics, culture, education, science and technology. It is a processing base of inland export commodities, an antecedent area for expansion of the reform and opening up, a development area in the policy of great western development implemented by the government and an experimental area for the country to balance urban and rural comprehensive coordinated reforms. In the past few years, Chongqing has been developed rapidly, so its demand on land increases. A study on the quantity of cultivated land resources in Chongqing helps to know about the influencing elements and the quantity in the supply and demand of cultivated land resources in Chongqing and also the most feasible development model.

\section{Establishment of the Model of Dynamic Change of Cultivated Land Resources in Chongqing}

\subsection{Determination of the Driving Factors in the Quantity Change of Cultivated Land Resources}

We divide the driving factors influencing the change of cultivated land in Chongqing City into there sub-systems, namely, the sub-system of population, the sub-system of technology (including the two sub-systems of multiple cropping index and per unit yield), and the system of cultivated land. These there sub-systems are interrelated and interactional.

\subsubsection{Population System}

The influence of population factor on utilization of cultivated land is mainly reflected in the number of population and distribution condition. Due to accretion of population, the pressure of demand on grain builds up and more land is used in agricultural production, which, generally, may lead to increase in the quantity of cultivated land. (Chen Meina, 2007) Nevertheless, the tendency between accretion of population in Chongqing and the change of the quantity of cultivated land is exactly the opposite, and as a whole, the area of cultivated land continuously declines with accretion of population. Increase of the demand on provisions under the progress of production technology can 
totally be realized in the situation of reduced amount of cultivated land. However, the influences of accretion of population on the construction land of residential land, social service facility and land for mining and industry are absolute and increased demand on construction land directly leads to decline of the amount of cultivated land.

\subsubsection{Determination of the Parameter of Population System}

The population structure that influences the change of the system of cultivated land is non-agricultural population and agricultural population (Chen Meina, 2007). In the population system, the two parameters of "change rate of non-agricultural population" and "change rate of agricultural population need to be determined. The two parameters are calculated to be respectively 0.05 and -0.01 after a reference to the yearbook of Chongqing. The non-agricultural population in Chongqing gradually increases, whereas the agricultural population reduces year by year.

The agricultural population and non-agricultural population in 2002 in Chongqing were respectively 23.92 million and 7.21 million, agricultural population accounting for $77 \%$ of the total population. Due to advancement of urbanization, the agricultural population by the year 2010 in Chongqing decreased to 21.96 million, whereas the non-agricultural population increased to 11.07 million, the agricultural population accounting for $66 \%$ of the total population.

\subsubsection{Major Formulas in Population System}

urbanization rate $=$ non-agricultural population/(agricultural population + non-agricultural population)

change of non-agricultural population= non-agricultural population * change rate of non-agricultural population

non-agricultural population $=$ INTEG (change of non-agricultural population,660.89

change of agricultural population $=$ change rate of agricultural population *agricultural population

agricultural population $=$ INTEG (change of agricultural population,2430.2)

\subsubsection{Sub-system of Technology}

The development level and application degree of scientific level directly affect the depth and breadth of land utilization. In agricultural production, technical progress improves the degree of intensification of agricultural production, enhances per unit yield of grain and alleviates pressure imposed by accretion of population and social and economic development on cultivated land (Wu Tao, 2006).

In the sub-system of technology, per unit yield of grain and multiple cropping index are used to represent the influence of technology in the amount of cultivated land.

\subsubsection{Sub-system of Multiple Cropping Index}

Multiple cropping index refers to the ratio of the total seeded area of agricultural crops to the area of cultivated land within a whole year. The climate in Chongqing is mild, a humid subtropical monsoon climate. The average temperature of the whole year is approximately $18^{\circ} \mathrm{C}$, and the average minimum temperature in winter is $6-8^{\circ} \mathrm{C}$. In summer, the weather is hot and the average maximum temperature each day in July is above $35^{\circ} \mathrm{C}$, providing good conditions for growth of agricultural crops. Moreover, owing to development of agricultural science and technology, the multiple cropping index is also, to some extent, increased. The average multiple cropping index in Chongqing from the year 2002 to the year 2010 was 1.52 according to the yearbook in Chongqing and the average change rate of the multiple cropping index was -0.00011 . As a whole, the multiple cropping index is slightly reduced and the reason for the reduction is related both with fluctuation of the area of cultivated land and the seeded area in those years. The higher the multiple cropping index, the smaller the pressure on cultivated land.

Major formulas in the sub-system of multiple cropping include the following:

change of multiple cropping index $=$ change rate of multiple cropping index*multiple cropping land index

multiple cropping land index = INTEG (change of multiple cropping index,1.51787)

\subsubsection{Sub-system of per Unit Yield of Grain}

Per unit yield of grain refers to the amount of grain produced per hectare of cultivated land in a whole year. Based on the original labor forces, area of cultivated land and natural conditions, the higher per unit yield of grain, the greater the influence of the technical level.

The average per unit yield in Chongqing from the year 2002 to the year 2010 was 4.54 tons/hectare. The per unit yield from the year 2008 to the year 2010 exceeded 5 tons $/ \mathrm{hm}^{2}$. The level of per unit yield increased year by year. 
Major sub-system formulas of per unit yield of grain include the following:

grain yield=area of grain land* per unit yield of grain

per unit yield of grain = INTEG (change of per unit yield,0.000415)

supply and demand ratio of grain=demand on grain/ grain yield

demand on grain $=$ total population * per capital grain

\subsubsection{Cultivated Land System}

2.1.3.1 The system of cultivated land is the core part of the entire system. The reasons for reduction of cultivated land mainly include occupation of cultivated land resources by economic construction, adjustment of the agricultural structure, ecological construction and damage of natural disasters (Liu, Kun, 2004). Accretion of cultivated land is mainly attributed to land consolidation, rehabilitation and reclamation.

The sub-system of cultivated land constitutes the balancing relationship of the system according to reduction and accretion of cultivated land. The amount of cultivated and affects demand on cultivated land and, furthermore, demand on grain. The total area of cultivated land in Chongqing in 2002 was 228252 hectares and the total area of cultivated land in 2010 was 223866 hectares, with fluctuation in between.

Major formulas include the following:

demand on cultivated land=demand on grain/(per unit yield of grain*ratio of grain land*multiple cropping index)

accretion of cultivated land $=$ area of cultivated land* accretion rate of cultivated land

area of grain land $=$ ratio of grain land*total seeded area

The system of cultivated land is a complex system. In addition to the influences of population system, economic system and technical system, other factors, such as, disaster damage and land clearing as well as agricultural policy would all affect the change in the quantity of cultivated land. In the meantime, the system of cultivated land is affected by these systems, and, in turn, it also affects development of these systems. The system of cultivated land is a dynamic and interactive changing system. 


\subsubsection{The Circuit Diagram of the Entire System}

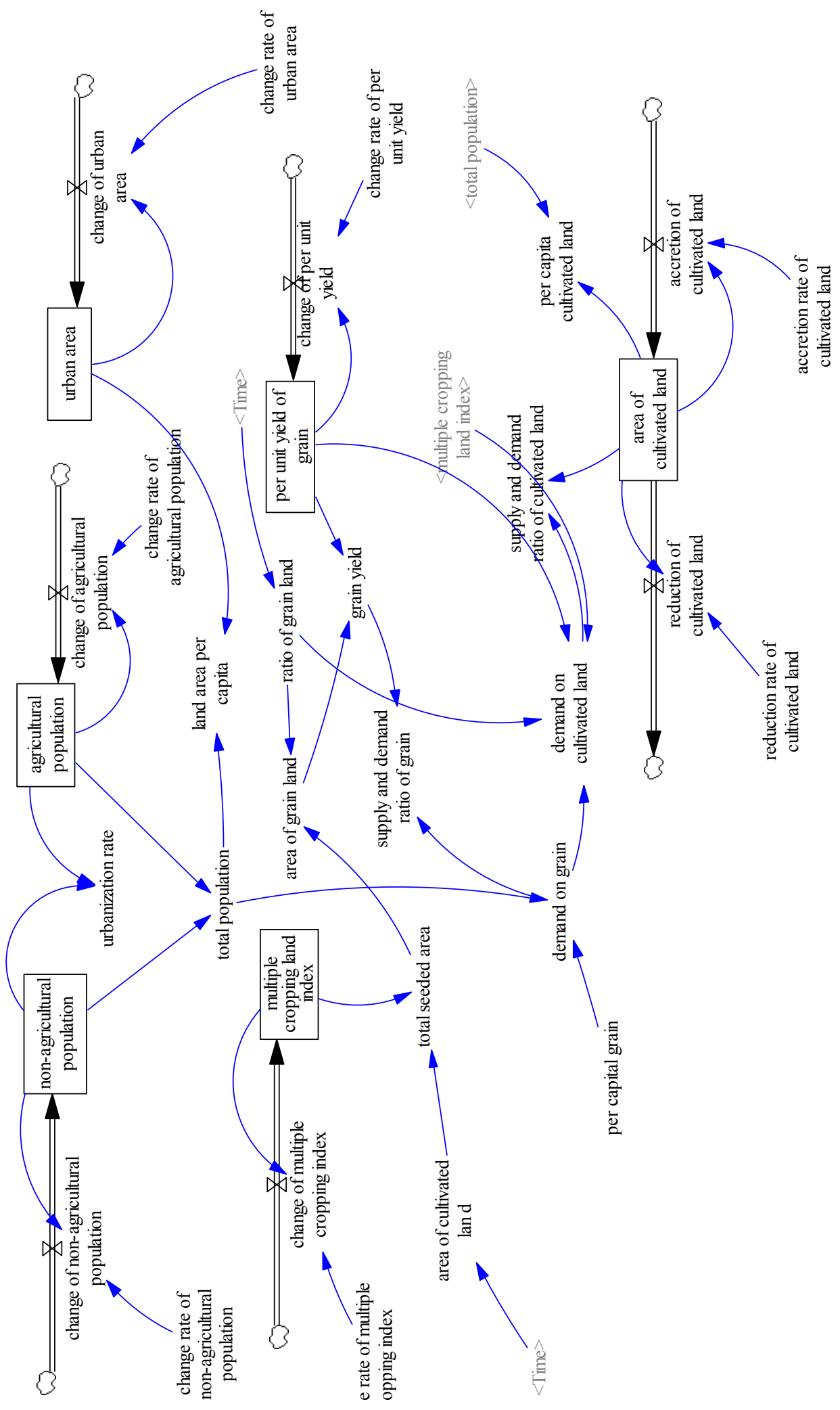




\section{Examination and Analysis of the Simulation Result}

\subsection{Historical Examination}

Historical examination means examination of the simulation behavior on the degree of fitting of the historical data of the system (Li Liande, 2009). It is to check the effectiveness of the model based on the relative error between the actual historical data and the simulation operation result and to verify whether the model established is effective by taking into consideration the degree of deviation of the data. The formula is as follows:

$$
D_{t}=\frac{X_{t}^{\prime}-X_{t}}{X_{t}} \times 100 \%
$$

Where, $\mathrm{Dt}$ is the degree of deviation, $\mathrm{Xt}$ ' is the value predicted and $\mathrm{Xt}$ is the actual value.

\subsection{The Mean Data between 2002 and 2010 Are Taken as the Parameters}

The simulation result is as follows:

1. Change of population: the change rate of non-agricultural population is 0.05 and the change rate of agricultural population is -0.01 .

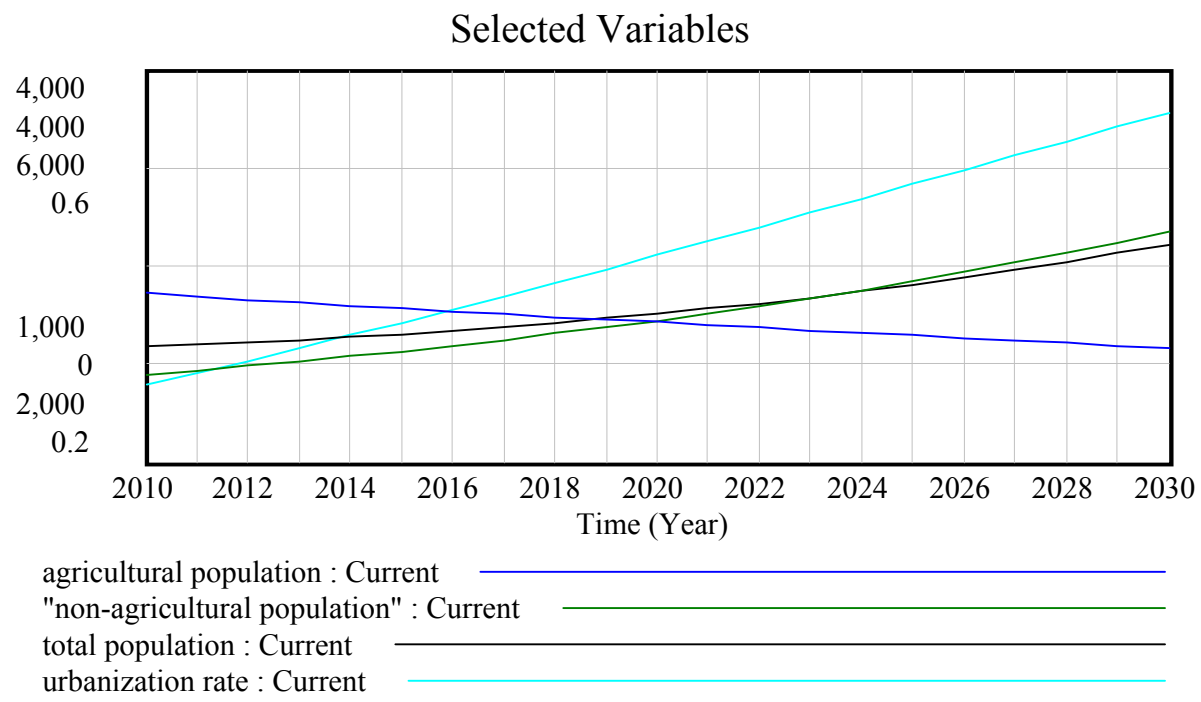

Figure 1. The simulation data diagram of population system

Result of historical examination:

Table 1. Result of historical examination of population in Chongqing

Unit: ten thousand

\begin{tabular}{cccccccccc}
\hline Year & $\begin{array}{c}\text { Agricultural } \\
\text { population } \\
\text { of the } \\
\text { model }\end{array}$ & $\begin{array}{c}\text { Actual } \\
\text { agricultural } \\
\text { population }\end{array}$ & $\begin{array}{c}\text { Discrepancy } \\
\text { rate }\end{array}$ & $\begin{array}{c}\text { Non-agricultural } \\
\text { population of } \\
\text { the model }\end{array}$ & $\begin{array}{c}\text { Actual } \\
\text { non-agricultural } \\
\text { population }\end{array}$ & $\begin{array}{c}\text { Discrepancy } \\
\text { rate }\end{array}$ & $\begin{array}{c}\text { Total } \\
\text { population } \\
\text { of the } \\
\text { model }\end{array}$ & $\begin{array}{c}\text { Actual } \\
\text { total } \\
\text { population }\end{array}$ & $\begin{array}{c}\text { Discrepancy } \\
\text { rate }\end{array}$ \\
\hline 2002 & 2430.2 & 2392.38 & $-1.58 \%$ & 721.45 & 721.45 & $0.00 \%$ & 3091.09 & 3113.83 & $0.73 \%$ \\
2003 & 2405.9 & 2376.18 & $-1.25 \%$ & 757.523 & 753.92 & $-0.48 \%$ & 3099.83 & 3130.1 & $0.97 \%$ \\
2004 & 2381.84 & 2358.4 & $-0.99 \%$ & 795.399 & 785.83 & $-1.22 \%$ & 3110.47 & 3144.23 & $1.07 \%$ \\
2005 & 2358.02 & 2351.88 & $-0.26 \%$ & 835.169 & 817.28 & $-2.19 \%$ & 3123.08 & 3169.16 & $1.45 \%$ \\
2006 & 2334.44 & 2353.44 & $0.81 \%$ & 876.927 & 845.43 & $-3.73 \%$ & 3137.76 & 3198.87 & $1.91 \%$ \\
2007 & 2311.1 & 2358.35 & $2.00 \%$ & 920.773 & 876.97 & $-4.99 \%$ & 3154.58 & 3235.32 & $2.50 \%$ \\
2008 & 2287.98 & 2349.67 & $2.63 \%$ & 966.812 & 907.38 & $-6.55 \%$ & 3173.64 & 3257.05 & $2.56 \%$ \\
2009 & 2265.1 & 2326.92 & $2.66 \%$ & 1015.15 & 948.69 & $-7.01 \%$ & 3195.04 & 3275.61 & $2.46 \%$ \\
2010 & 2242.45 & 2196.45 & $-2.09 \%$ & 1065.91 & 1107 & $3.71 \%$ & 3218.89 & 3303.45 & $2.56 \%$ \\
\hline
\end{tabular}


From the examination result, the discrepancy rate of both the total population and the agricultural population is controlled within $3 \%$, whereas the discrepancy rate of non-agricultural population has large fluctuation.

2. The reduction rate of cultivated land is set at 0.00165 and the accretion rate of cultivated land is set at 0.000001 . The simulation result is:

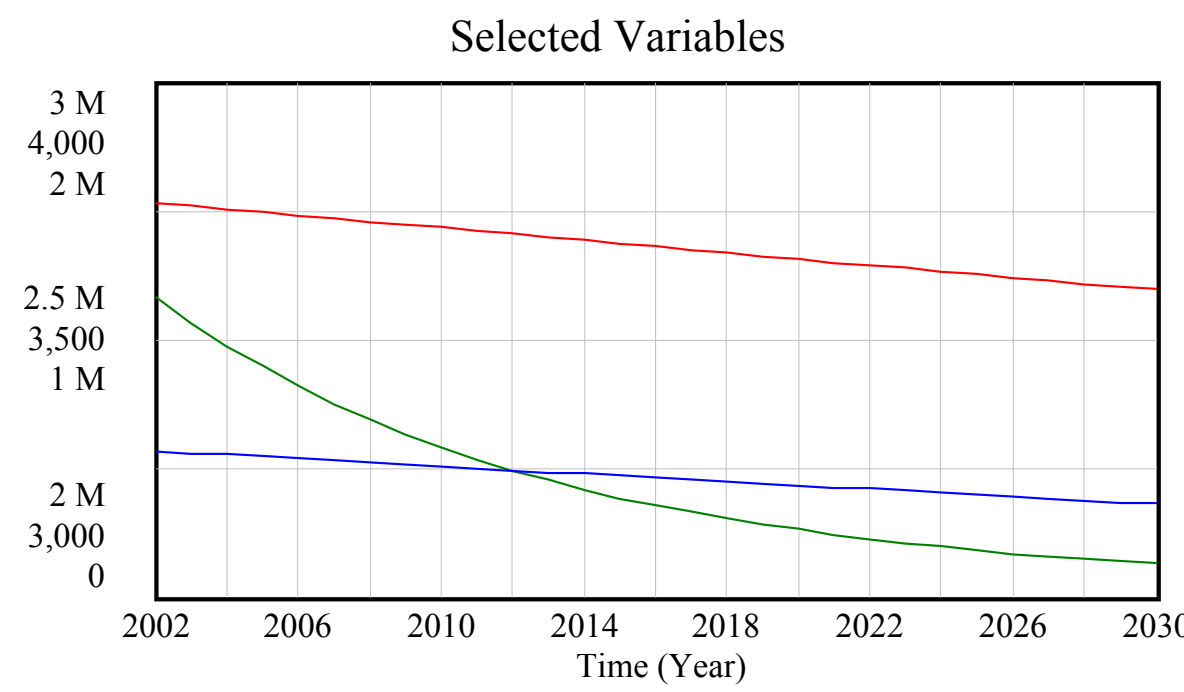

area of cultivated land : Current

reduction of cultivated land : Current

supply and demand ratio of cultivated land : Current

Figure 2. The simulation data diagram of the supply and demand ratio of cultivated land

The area of cultivated land will reach 220114 hectares by the year 2024. And the supply and demand ratio of cultivated land will change from 1.17 in 2002 to 0.79 in 2024. The situation of supply falling shorting of demand will appear.

Table 2. Result of historical examination of the area of cultivated land in Chongqing

Unit: hectare

\begin{tabular}{cccc}
\hline Year & $\begin{array}{c}\text { Simulative } \\
\text { cultivated } \\
\text { land area }\end{array}$ & $\begin{array}{c}\text { Actual } \\
\text { cultivated } \\
\text { land area }\end{array}$ & $\begin{array}{c}\text { Discrepancy } \\
\text { rate }\end{array}$ \\
\hline 2002 & 2282530 & 2282525 & $0.00 \%$ \\
2003 & 2278770 & 2144365 & $5.90 \%$ \\
2004 & 2275010 & 2105852 & $7.44 \%$ \\
2005 & 2271260 & 2067634 & $8.97 \%$ \\
2006 & 2267510 & 2052255 & $9.49 \%$ \\
2007 & 2263770 & 2239082 & $1.09 \%$ \\
2008 & 2260040 & 2235932 & $1.07 \%$ \\
2009 & 2256310 & 2235932 & $0.90 \%$ \\
2010 & 2252590 & 2238667 & $0.62 \%$ \\
\hline
\end{tabular}

3. Content of simulation of other data: 
Table 3. Result of historical examination of the area of cultivated land in Chongqing Unit: 0.1 billion Yuan

\begin{tabular}{cccc}
\hline Year & $\begin{array}{c}\text { Simulative } \\
\text { total } \\
\text { production } \\
\text { value }\end{array}$ & $\begin{array}{c}\text { Actual } \\
\text { total } \\
\text { production } \\
\text { value }\end{array}$ & $\begin{array}{c}\text { Discrepancy } \\
\text { rate }\end{array}$ \\
\hline 2002 & 2232.86 & 2232.86 & $0.00 \%$ \\
2003 & 2606.86 & 2555.72 & $-2.00 \%$ \\
2004 & 3043.51 & 3034.58 & $-0.29 \%$ \\
2005 & 3553.3 & 3467.72 & $-2.47 \%$ \\
2006 & 4148.48 & 3907.23 & $-6.17 \%$ \\
2007 & 4843.35 & 4676.13 & $-3.58 \%$ \\
2008 & 5654.61 & 5793.66 & $2.40 \%$ \\
2009 & 6601.76 & 6530.01 & $-1.10 \%$ \\
2010 & 7707.55 & 7925.58 & $2.75 \%$ \\
\hline
\end{tabular}

The total production value has large fluctuation, so the parameters need to be adjusted.

Table 4. Result of historical examination of the area of construction land in Chongqing Unit: hectare

\begin{tabular}{cccc}
\hline Year & $\begin{array}{c}\text { Simulative } \\
\text { construction } \\
\text { land area }\end{array}$ & $\begin{array}{c}\text { Actual } \\
\text { construction } \\
\text { land area }\end{array}$ & $\begin{array}{c}\text { Discrepancy } \\
\text { rate }\end{array}$ \\
\hline 2002 & 55989 & 55989 & $0.00 \%$ \\
2003 & 61684 & 65495 & $5.82 \%$ \\
2004 & 67958 & 64778 & $-4.91 \%$ \\
2005 & 74870 & 73287 & $-2.16 \%$ \\
2006 & 82486 & 81071 & $-1.74 \%$ \\
2007 & 90876 & 87270 & $-4.13 \%$ \\
2008 & 100119 & 93304 & $-7.30 \%$ \\
2009 & 110302 & 102684 & $-7.42 \%$ \\
2010 & 121522 & 113653 & $-6.92 \%$ \\
\hline
\end{tabular}

Parameters of actual construction land area and simulative construction land area also need to be adjusted.

Large fluctuation exists between all simulative numerical values and the actual numerical values. The reason is that the influences of a lot of parameters on the future are linear because the authors made the prediction with the average development level between the year 2002 and 2010. However, the actual development process is non-linear. In the process of adjustment of parameters, it is necessary to pay attention to the linear change of the data.

\section{Different Simulation Projects to Change Parameters}

\subsection{Influence of Change of per Unit Yield on the Supply and Demand Ratio of Cultivated Land}

The change rate of 0.013 (mean value) of per unit yield and the change rate of 0.1 (improvement of scientific level) of per unit yield both have influences on the supply and demand ratio of cultivated land. The two different kinds of change in per unit yield make the supply and demand ratio of cultivated land increase in different forms. 


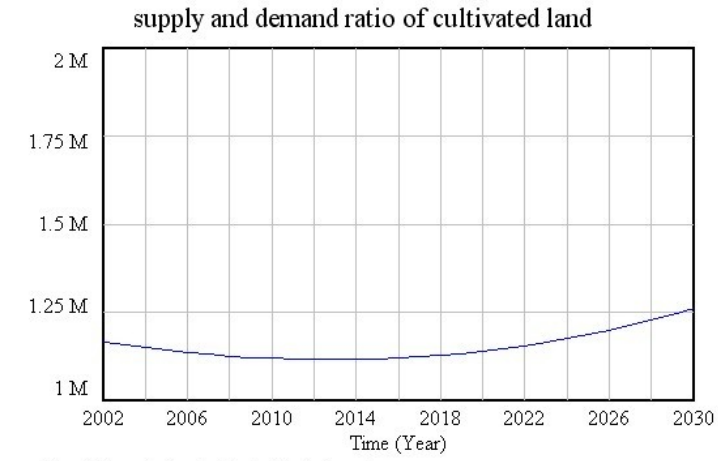

supply and demand ratio of cultivated land : Current

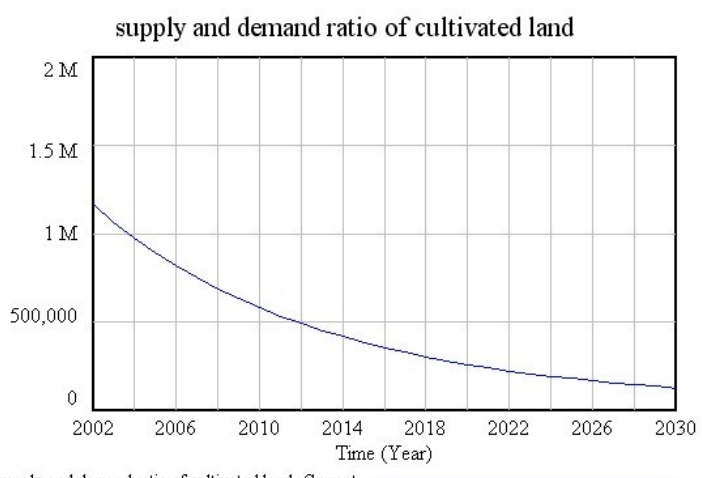

supply and demand ratio of cultivated land : Current

\subsection{Influence of Change of per Unit Yield on the Demand on Cultivated Land}

Increase in the per unit yield has certain effect of adjustment on the supply and demand ratio of cultivated land in that it stabilizes the market demand on land and avoids waste of cultivated land and change of the structure. Change of per unit yield is mainly manifested in its influence on the change of demand on cultivated land.
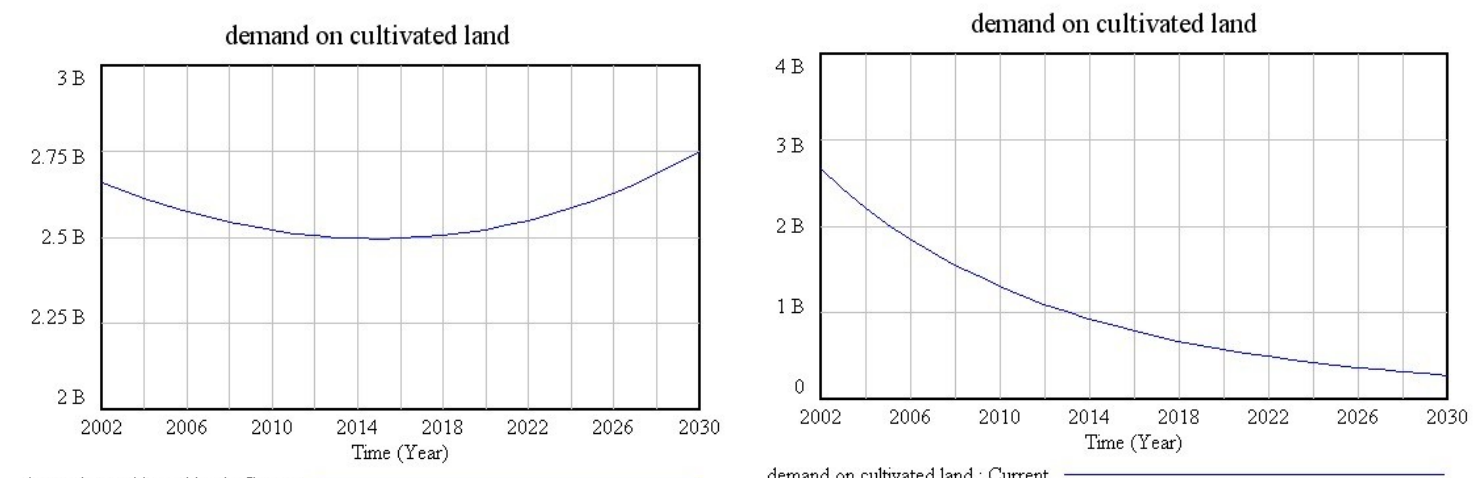

demand on cultivated land: Current

demand on cultivated land: Current

When the change rate of per unit yield is 0.013 (mean level), the fluctuation of demand on cultivated land is relatively small, whereas when the change rate of per unit yield is 0.1 (improvement of scientific and technical level), the demand on cultivated land decreases in a linear form.

\subsection{Concluding Remarks}

There are a lot of factors and systems that affect both the quantity and demand of cultivated land resources. At the time when these systems affect the quantity of cultivated land, they are also affected by the quantity of cultivated land. This is an interactive system in which all factors constrain mutually. Either single accretion of non-agricultural population or single accretion of agricultural population may impose pressure on the system of cultivated land. Change of the population system will directly affect both the demand and quantity of cultivated land. The technical level has certain effect on the quantity of cultivated land. Thus, it is necessary to pay attention to the intensive use of land, enhance the multiple cropping index and per unit yield and emphasize the effect of science and technology.

First of all, it is necessary to strengthen scientization and informatization of land management and to realize rational supervision and utilization of cultivated land by means of timely and effective prediction, assessment or evaluation, decision-making and planning (Chen Yuhong, 2009). This enables management of the system to possess the function of dynamic monitoring and updating. Then, it is necessary to set up a correct concept of political achievement, change the previous political achievement assessment standard in which GDP is the core and strengthen sustainable development of regional economy and observation of such indexes as the environment and ecological protection. It is also necessary to reinforce specialized planning of land utilization and planning and design of land utilization and make an expected arrangement and planning on development and utilization of land resources to ensure rational and effective use of land resources. Finally, we need to carry out the basic national policy of "Highly cherishing, rationally using land and practically protecting land" and continue to enlarge the protection vigor of cultivated land, especially basic farmland. 


\section{References}

Chen, Meina. (2007). Research on the Sustainable Development of Population and the Cultivated Land in Inner Mongolia. Capital University of Economics and Business.

Chen, Yuhong. (2009). Study on Reasonable Supply Scale of Land for Urban Construction in Chongqing. Chongqing University.

Li, Liande. (2009). Systems Dynamics Research of Chinese Energy Supply and Demand. Northeastern University.

Liu, Kun. (2004). Evaluation, Monitoring and Early-warning on Total Dynamic Balance of Cultivated Land. Shandong Normal University.

Wu, Tao. (2006). Study on the Change of Cultivated Land Use and Dynamic Simulation in Guangzhou City. Guangzhou University.

Xu, Ruixiang, Zhang, Yongqin, Ding, Jianzhong, \& et al. (2002). Research on Model for Regional Total Dynamic Balance of Cultivated Land-- A Case Study in Wenzhou City. Economic Geography, (4), 435-439. 